\title{
Gendered health care labour markets? A case study of anatomical pathologists and haematologists in KwaZulu-Natal, South Africa
}

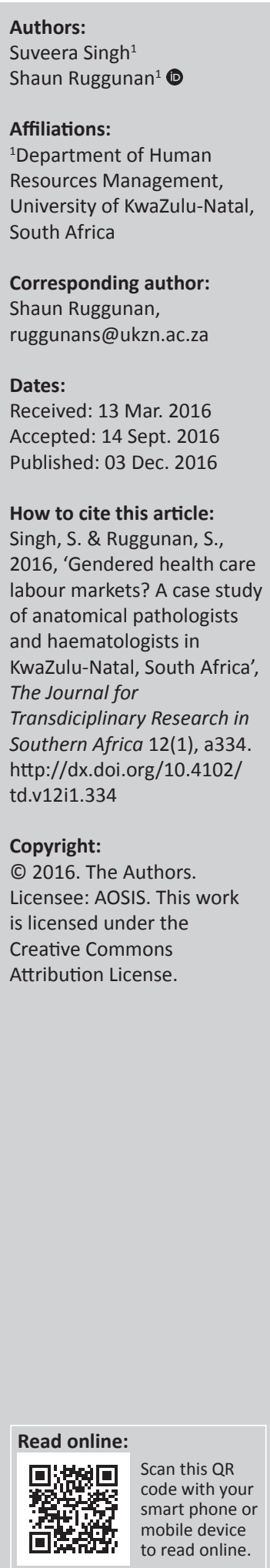

This study qualitatively explored the role of gender and related factors that influence medical doctors' decisions in selecting a specialisation within medical laboratory medicine. This study is novel in that it disaggregates doctors by specialisation. It further focuses on non-clinical medical specialists who have been ignored in the global human resources for health literature. Hakim's preference theory as well as socialisation theory is adapted to explain some of the reasons female doctors make certain career choices regarding specialisation within the medical field. The study focused on laboratory doctors in the public and private sector in KwaZuluNatal. A qualitative approach was adopted given the small population size and the need for an interpretive approach to the data. The research design was an exploratory case study and thematic analysis was used to discover the relevant themes. The non-probability purposeful sample comprised a total of 20 participants, of which 11 were anatomical pathologists and 9 were haematologists, all based in KwaZulu-Natal, South Africa. Data collection was performed via in-depth interviews. Trustworthiness of the data was ensured through methods of credibility and triangulation. The key finding is that although gender is a significant factor in career choice (for specific disciplines), it is one of many factors that determine self-selection into a specific medical laboratory specialisation. The conclusions, although not generalisable, have implications for human resources for health policies targeted at achieving higher levels of recruitment in laboratory medicine as a profession.

\section{Introduction}

The purpose of this article is to explore the role of gender dynamics in doctors' choices of medical laboratory specialisation. Most of the global and national literature on human resources for health focuses on clinical practitioners (Brandis et al. 2016:240; Hongoro et al. 2016:73; Maier \& Aiken 2016:3; Reich, Hansen \& Link 2016:6). Clinical practitioners are health practitioners who interact directly with patients. There is a gap in the empirical and theoretical work on medical specialists who work in non-clinical settings (Holleyman \& Jones 2016; Raghuram \& Kofman 2002:2074; Ruggunan 2013:100; Young et al. 2003:14). It is within this context that this article hopes to contribute by extending our empirical knowledge of non-clinical doctors.

Laboratory medicine refers to a medical specialisation in which pathologists provide testing of patient tissue samples (Drexel University College of Medicine 2014). Medical laboratory medicine has several branches or disciplines. These are anatomical pathology, haematology, chemical pathology and virology. This study focuses on the specialisations of anatomical pathology and haematology. Anatomical pathologists are specialists who deal with the tissue diagnosis of diseases (Royal College of Pathology of Australia 2011). Therefore, anatomical pathologists require a broad-based knowledge and understanding of the pathological and clinical aspects of many diseases (Holleyman \& Jones 2016; Raghuram \& Kofman 2002:2075; Ruggunan 2013:101; School of Laboratory Medicine \& Medical Sciences, UKZN 2014; Young et al. 2003:18). The specialisation involves the diagnosis of potential disease and malignancies based on the analysis of biopsied tissues and sometimes consists of post-mortem investigation (School of Laboratory Medicine \& Medical Sciences, UKZN 2014). Haematologists specialise in the branch of pathology in which components of diseases that affect blood are studied (Singh 2013:12).

In terms of patient care and clinical decision-making, laboratory medicine is required in more than $80 \%$ of clinical decision-making at all levels from outpatient care for ambulant patients to inpatient care for critically ill patients (School of Laboratory Medicine \& Medical Sciences, UKZN 2014). Both anatomical pathologists and haematologists are critical to the South African healthcare system. They service both the private and public healthcare markets in South Africa. 
Increasingly, both the private and public sectors are forming partnerships to facilitate healthcare delivery (Michel 2016; Tsiko 2016).

Given the alarming epidemic rates of HIV and/or AIDS and tuberculosis in South Africa (Michel 2016), both anatomical pathologists and haematologists contribute significantly to the healthcare chain in diagnosing communicable diseases via biopsies and blood samples. Clinicians are unable to begin appropriate clinical treatments and management of their patients without these initial non-clinical assessments by these medical laboratory specialists. An adequate level of healthcare professionals must be available in order to efficiently maintain the health of the population. However, as outlined by Naidoo (2012:149), Ruggunan (2013:101), Ruggunan and Singh (2013:4), Cassim and Ruggunan (2014:2), Pathcare (2015), Michel (2016) and Tsiko (2016), a shortage of key human resources exists in the health sector including medical laboratory specialisation exists.

It must be noted that non-clinical work is a crucial part of medicine (Hajjaj et al. 2010; Joyce et al. 2015; Tsiko 2016). Most studies on gender and career choice in medicine have been conducted on male-dominated clinical specialisations (Riska 2003:60). In addition, studies of female physicians and career choices and experience of work have been conducted on women who are general practitioners, or in primary care contexts (Riska 2003:71). Further studies by Heald et al. (2016) and Lu (2016) support Riska's claims. This study addresses this gap through a focus on two non-clinical medical specialisations: anatomical pathology and haematology.

The South African labour market comprises 278 anatomical pathologists and 147 haematologists (HPSCA 2016). The discipline of anatomical pathology is male dominated in KwaZulu-Natal (KZN), with only 11 of the 32 anatomical pathologists being female (HPSCA 2016). At national level, only 113 of the 278 anatomical pathologists (or 40\%) are female. Haematology by contrast is female dominated both provincially and nationally. In KZN, 11 of the 18 haematologists are female and nationally 92 (63\%) of the 147 haematologists are female.

\section{Adapting Hakim's preference theory and the socialisation theory}

Hakim's preference theory is a sociological theory that can be used to explain the changes that women have experienced in contemporary societies in relation to two main lifecycle patterns, namely fertility and employment (Vitali et al. 2009:7). Hakim's preference theory has been used in several studies, such as Yee Kan (2005), Hakim (2006), Manea (2007) and Hakim (2011), to explore work-family life balances of women. Increasingly, the theory is used by human resources practitioners and theorists to explain career preferences of women in countries, like South Africa, that have legislated liberal and egalitarian policies towards women yet continue to experience gendered professional labour markets. According to Hakim (cited in Vitali et al. 2009:18), women in more egalitarian societies are more likely to exercise their preferences to follow certain career paths or to remain at home to raise their families rather than these being decisions of patriarchal legislation or cultural norms. In societies that are egalitarian, such choices are seen as having equal value, because structural obstacles to women's employment have legislatively been removed, and therefore the choice made by women is viewed as a 'free choice'. Hakim (cited in Vitali et al. 2009) explains that there are three types of women who are evenly distributed across industrialised societies and societies that have egalitarian labour market legislation. The three types of women are family-oriented, career-oriented and adaptive women. Family-oriented women have family life as the main priority and unusually opt not to work. Career-oriented women focus on work and generally remain childless. Adaptive women, however, combine work and family life and obtain the best of both worlds. In other words, there is a trade-off between family and career. These women may move into part-time work after childbirth (Vitali et al. 2009:8). For purposes of this study, it is the latter category, adaptive women, that is of key concern.

However, Hakim's theory can be enhanced by combining elements of socialisation theory. Socialisation theory has many proponents depending on its disciplinary origins. For purposes of this article we draw on contemporary gendered socialisation theory as proposed by Carter (2014). Carter (2014:245) and Riska (2003:61) maintain that girls and boys are socialised differently and hold different values and expectations about their sex roles and tasks as adults. Through symbols and language, Carter (2014:244) argues that children are gendered into certain behaviours from birth itself. Language for boys is centred on physical characteristics, whereas girls are addressed in terms of expressivity and affection (Carter 2014). Career choices are made in agreement with expected gender positions that they are expected to occupy in the family. Men are seen as more career oriented, whereas women make career choices that depend on their skills. However, they also make career choices at a later stage that can accommodate work as well as family demands (Carter 2014:245; Riska 2003:70). Once again, it is evident that the ways in which one is socialised individually influence one's choices, even in terms of careers.

\section{Factors affecting choice of specialisation}

Gender plays a role in the choice of medical specialisation (Bhat, D'Souza \& Fernandez 2012). Both male and female students receive the same education; however, it is noted that the distribution of gender across several medical specialities is not proportionate (Van Tongeren-Alers et al. 2013). Such an imbalance within specialities may have an impact on the physician workforce in future (Bhat et al. 2012; Van TongerenAlers et al. 2013). This is an indication that there are numerous factors that attract male and female specialists differently. In other words, there are variances in the specialities that attract males and females (Chung et al. 2013; Eze et al. 2011). The additional factors that influence the choice of medical 
specialisation have been classified as personal interest, career prospects, lifestyle, job security, appraisal of own skills, hours of practice, scope and the influence of parents/family (Bhat et al. 2012; Correia Lima de Souza et al. 2015; Eze et al. 2011; Gour et al. 2011; Van Tongeren-Alers et al. 2013).

\section{Research design}

The research design of this study is an exploratory case study. Exploratory studies are particularly important in understanding new phenomena in areas where little empirical work has been done before (Saunders, Lewis \& Thornhill 2012). Based on an extensive review of the literature, we assert that there is limited empirical work on medical laboratory specialists in South Africa; therefore, this research design is appropriate. This type of case study is more attuned to uncover qualitative experiences of participants and the reasons that they select themselves into the anatomical pathology and haematology professions, rather than establish causal mechanisms between two or more variables (Bryman \& Bell 2007:30; Burton 2000:54). Exploratory case studies are important in that they serve as building blocks for future large-scale quantitative studies (Burton 2000:87; Gummesson 2000:11; Saunders et al. 2012). Qualitative studies are relevant when there is a need to gather meaningful data that are rich in details. Given the small population of these specialists in $\mathrm{KZN}$, a qualitative study is deemed appropriate.

\section{Sampling}

Non-probability sampling was used in this research study. The sampling technique used for this study was purposive sampling. Purposive sampling is a technique in which participants of a study are selected based on their qualities and certain criteria necessary for the study (Etikan, Musa \& Alkassim 2016). Participants were chosen based on their specialisation, that is, whether they were anatomical pathologists or haematologists practising in a permanent position in KZN. These were the only criteria applied in purposively selecting the sample. The study sample comprised a total of 20 participants. Of the participants, 11 were anatomical pathologists, representing $39 \%$ of the total population of anatomical pathologists in KZN in 2013. In addition, nine haematologists were interviewed. The total percentage of haematologists interviewed constituted $81 \%$ of the total haematology population of KZN in 2013.

\section{Data collection}

In-depth face-to-face interviews (conducted by the researcher who as a social scientist has had previous experience and expertise both theoretically and practically in the interview process) with participants were the key method of data collection for this study. The interviewer was therefore an 'outsider' and a neutral person in conducting interviews with participants. Interviews allow for construction and reconstruction of knowledge through the interaction between participant and interviewer. A flexible structure (probing where necessary) is possible, while at the same time direction and focus can be maintained as the interviewer is present
(Edwards \& Holland 2013). Field notes were also taken to supplement data. Interviews were recorded with a digital voice recorder and thereafter transcribed by a professional. Each interview lasted approximately 1 hour. Interviews were conducted in 2013 and were all off-site. By 'off-site', it is meant that venues other than the place of work for participants. The interview schedule, with the core themes based on the role of gender in medical specialisation as well as other factors that influenced the same, was open ended and allowed for probing.

\section{Data analysis}

Data for this study were analysed through thematic analysis. Thematic analysis refers to a process for the identification, analysis and reporting of 'patterns' or themes within data (Braun \& Clarke 2006, cited in Judger 2016). Themes were manually coded in this case study by way of categorising them into different themes or patterns, and developed through consistent and thorough reading of all interview transcripts repeatedly. The factors that contributed to the choice of specialisation within medical laboratory specialisation were categorised using Braun and Clarke's (2006:80) method of thematic analysis. This consisted of six steps and was an iterative process. The six steps include the following: familiarising yourself with data, generating initial codes, searching for themes, reviewing themes, defining and naming themes and producing the report (Braun \& Clarke 2006). Although recurring concepts and ideas were coded as patterns, the researcher also noted minority views in the data. These temporary themes were then revised and further reduced through an iterative process of recoding the data also known as progressive coding.

\section{Trustworthiness of data}

To ensure trustworthiness of the data, the framework as proposed by Babbie and Mouton (2009:407) was used. This included credibility, transferability, dependability and confirmability. Credibility was achieved through a prolonged period of engagement with participants during the fieldwork process. Engagement consisted of several initial meetings with participants before interviews in order to establish trust. This also consisted of observing work processes at the sites of work. This was enhanced by purposive sampling, peer debriefing and the experiential and academic expertise of the researchers. Transferability was enhanced by purposively selecting the participants based on their experience and expertise (Babbie \& Mouton 2009:128). Dependability was achieved by maintaining an audit trail of the research process. This allows for greater transparency of the research process and verification of findings against the raw data. Given that this was part of a larger research project, both researchers in this project coded the data independently to generate themes. Both sets of themes were then compared to achieve a measure of credibility and trustworthiness of the data analysis process. After the initial coding process, both researchers discussed how to label, collapse and disaggregate themes where needed. Interview data were also triangulated 
against available labour market statistics and empirical findings from other studies to ensure a level of credibility. A high participation rate of the population also ensured trustworthiness. Confirmability was realised by allowing participants to read transcripts of their interviews as a way of ensuring that the interviews were accurately transcribed.

\section{Ethical considerations}

This study has been granted full ethical approval from the University of KwaZulu-Natal Ethics Committee.

\section{Findings}

In exploring the role of gender in relation to the choice of specialisation under the medical umbrella, several themes were identified. Evidently, findings illustrate that gender as an isolated or independent concept is not the only contributing factor towards choice of specialisation within the medical profession. Findings have been categorised into five broader themes: flexibility; gender, 'love' and commitment for the discipline; personal career choice regardless of gender and exposure to non-clinical disciplines during undergraduate studies.

\section{Levels of flexibility offered by medical laboratory disciplines}

Flexibility appears to be an attraction within most medical laboratory disciplines at large as indicated by one of the participants:

'... I think that any laboratory speciality gives- awards you a little bit of flexibility.' (Participant 1: Interview 23 August 2013: Durban)

Furthermore, findings reveal that certain laboratory disciplines boast more flexibility than others. Flexibility within the discipline of haematology specifically can be much higher as opposed to other medical laboratory disciplines, as mentioned by Participant 4 :

'... with haematology what you can do is you could go either into the laboratory side or you can go into the clinical side. And you can actually- if you have got dual speciality - you can move between the two. So you can either choose to work in the laboratory or you can choose to work with patients. There is ayou have to do extra years to specialise in both areas. So there is a bit more flexibility I think with haematology compared to say chemistry or micro or histopathology - where those are pure pathology disciplines, whereas haematology you do have this option to go into clinical.' (Participant 4: Interview 30 August 2013: Durban)

Another participant expressed similar sentiments as above:
'... You can do lots of things. And in the lab you can't really have a laboratory based anatomical pathologist. You can do flow, you can do immunology, you can do blood transfusions.' (Participant 3: Interview 24 August 2013: Durban)

When taking a closer look particularly within the discipline of haematology, flexibility appeared to be a major influential factor in determining career choice not only within the medical field but also within the realm of medical laboratory specialisation as a whole. Flexibility within the haematology discipline exists even in the nature of work processes as activities. Gour et al. (2011) indicate that wider scopes of certain medical specialities are an influential factor in choice of careers. As mentioned earlier, the discipline of haematology offers the flexibility of manoeuvring between clinical and laboratory settings. As expressed by a respondent:

'... One of the advantages that I mentioned earlier was that you can move between clinical and laboratory. And that is a big advantage. The nice thing is you can do a bone marrow biopsy, see the patient and come to lab and interpret the sample yourself.' (Participant 2: Interview 4 May 2013: Durban)

A similar, more detailed account of flexibility with haematology is expressed by another respondent as follows:

'... haematology offers you both lab and clinical- You have got two branches in clinical. You have the oncology branch and the general non-malignant branch.' (Participant 3: Interview 24 August 2013: Durban)

The nature of working hours affects how 'flexible' a medical discipline may be. Gour et al. (2011) and Bhat et al. (2012) found that working hours serve as a factor that influences the choice of medical speciality. The duration of working hours may attract or drive away medical professionals, as indicated by one of the participants when questioned on whether or not flexibility influences a choice of specialisation:

'... definitely, flexibility in the department and working hours being fixed- definitely it would, it has been one of the main reasons that I joined the department and I think it's a draw card for a lot of people.' (Participant 2: Interview 4 May 2013: Durban)

Similarly, an anatomical pathologist expressed the following regarding working hours:

'... it's more flexible - yes - because a lot of the private sector pathologists, allow you part-time work ...' (Participant 5: Interview 17 May 2013: Durban)

Although flexibility does play a role in determining a specialisation within the medical field, it is not the only reason as will be elaborated in this article. This is expressed by a respondent when questioned on whether or not flexibility affects the choice of speciality:

'... I don't think it's the prime reasons that I chose it at all.' (Participant 1: Interview 23 August 2013: Durban)

\section{The role of gender in determining choice of specialisation}

As indicated by Bhat et al. (2012), Van Tongeren-Alers et al. (2013) and Correia Lima de Souza et al. (2015), gender is influential in determining the choice of specialisation. Findings of this study indicate that gender does play a role in determining specialisation within medical laboratory medicine. When asked if gender affects a decision regarding which specialisation is selected as a career choice within the 
medical field, the majority of the participants agreed. Some participants felt that laboratory disciplines generally are dominated by females. The following quote is an expression of the above sentiment:

'The nature of work is day based as opposed to after hours. Pathology per se is female dominated. Aside from the fact more female doctors are qualifying now as doctors, so the whole graph is skewed as well. When it was my choice as well- because of these reasons.' (Participant 1: Interview 23 August 2013: Durban)

In addition to this, another respondent expressed the following:

'... Females, in fact, all the laboratory based disciplines have lots of females. One, it takes females out of seeing patients in the wards. The other thing- it gives them a bit of set hours and it's not so stressful- and being on call. Most of the calls you have are telephonic in the laboratory and so females are still be able to spend time with their family and take care of their children ...' (Participant 3: Interview 24 August 2013: Durban)

Another respondent emphasised the issue of females and family life:

'... I think it does, definitely. Pathology has always been seen as a very stable type of environment where your hours are fixed and therefore it attracts female colleagues - yes it definitely plays a role. In our department - we are female dominated.' (Participant 2: Interview 4 May 2013: Durban)

Pathology as a discipline within the medical field appears to be chosen by females because of commitments to their families, their roles as wives and mothers, the flexibility of work itself, as well as working hours. As indicated by a respondent below:

'... but the reality is that a lot of them are married and have kids and have a family life ... working nine to five Monday to Friday and that is it. And a lot of females tended to choose that [pathology] because it's amenable to their family life.' (Participant 2: Interview 4 May 2013: Durban)

In a similar manner, the concept of gender and working hours being a contributing factor for females in deciding a speciality can be reinforced further as follows:

'But I have noticed that a lot of females tend to be attracted not only to haematology but laboratory disciplines per se. I think the hours- the operating hours are good, it's usually standard operating hours. I am talking as a registrar as well from training level. There are weekend calls but its half day and you don't have to be on site. If there are problems, queries you are at reach via your cell phone. And if there is a reason for you to come in yes you can come in.' (Participant 1: Interview 23 August 2013: Durban)

Although there is said to be many females within the laboratory discipline, one participant highlighted that despite this males are still part of pathology:

'... and when you go to conferences as well, there is a lot more females. I wouldn't say a lot more females because in certain departments you find that there are quite a few males involved in pathology. But it is generally a female dominated department, yes.' (Participant 2: Interview 4 May 2013: Durban)
Another point of note is that although laboratory disciplines tend to attract females who assume the roles of wives and mothers, this is not the sole reason for their choice of specialisation as one participant who is not a mother expresses in the following:

'... your gender? For me ... I don't have any children. I think if you look at it generally it probably does.' (Participant 12: Interview 20 June 2013: Durban)

Interestingly, within the discipline of medical laboratory medicine, haematology is found to attract more females than most other pathology or laboratory disciplines. This can be indicated through the following participant:

'Haematology as a discipline attracts more females and I would say things like virology, chemical pathology, microbiology as well because of the nature of the work. Although haematology training is partly clinical, the calls after hours- calls that we do are not on site, they are telephonic, working hours are 8 to 4 and even the calls during the week are once a week. You have a lot more free time for family and I think for females with families and children, it allows you to divide your time without feeling that you are neglecting family.' (Participant 6: Interview 26 May 2013: Durban)

Importantly, one must note that there has been an increase in the number of females graduating in haematology. As Participant 1 highlights:

'Yes, there's ONLY been females. Hard to get a male [graduate] now. Dominated by females. Even when I go to conferences, it is female dominated.' (Interview 23 August 2013: Durban)

It must be noted, however, that haematology cannot be seen as a 'soft discipline', as highlighted by the following respondent:

'... I don't think it's a soft job for a female. You have a choice of doing clinical work and laboratory work and as a mother and wife, its [sic] easier to have certain - so you have your second job to go to when you leave work.' (Participant 10: Interview on 4 May 2013: Durban)

Moreover, haematology is not seen by all participants as attractive only to females. Participant 10 emphasises this:

'No, I would not say that. Any laboratory discipline gives you a certain amount of flexibility and it also allows you to decide where you want to work- hours you want to work ... no, it does not attract more females.' (Participant 10: Interview on 4 May 2013: Durban)

In addition to the issue of working hours, anatomical pathology is seen as having much more demanding working hours than haematology, which may be influential in driving females (who are mothers) away. As expressed by a participant:

'... a lot of people are dissuaded from anatomical pathology because of their long working hours. They might not do calls on weekends but their working hours are seven to six and it is intense.' (Participant 6: Interview 26 May 2013: Durban)

Another respondent reinforces the abovementioned:

... hours are long- 7h30 to $18 \mathrm{~h} 00$... No flexibility in anatomical pathology ... (Participant 7: Interview 24 August 2013: Durban) 


\section{Love and commitment for the discipline}

It is clear that an inherent 'love' for a particular discipline played a vital role in decisions regarding choice of specialisation. Hence, choosing a discipline was not solely attributed to being male or female, but based on passion or innate drive for a certain specialisation and its labour process. Correia Lima De Souza et al. (2015) identified social commitment as a factor affecting choice of specialisation. As expressed by a respondent:

'... I think definitely is, because I know with my female friends when they were choosing a speciality because some of them chose purely based on the fact that they loved the speciality ...' (Participant 5: Interview 17 May 2013: Durban)

Personal interest for the discipline has also been a contributing factor in this study similar to findings identified by Gour et al. (2011):

\footnotetext{
'I was interested in haematology- my interest actually stemmed when in the UK and I worked in a haematology unit there. And that is where my interest grew in haematology.' (Participant 1 : Interview 23 August 2013: Durban)
}

The nature of work is influential in attracting doctors into the field, again based partially on one's personal interests. As highlighted by Participant 2:

'Though I must admit when you speak to a lot of colleagues ... a lot of them cannot see themselves sitting behind a microscope. And sitting behind papers and interpreting ... so without a commitment or love for that process, you won't succeed. It's not patient contact based which some doctors thrive on.' (Participant 2: Interview 4 May 2013: Durban)

In addition to this, another participant emphasised the following which demonstrates that one's personal interests and likes determine one's choice of specialisation within the medical laboratory field:

'what doesn't appeal to them about an anatomical pathologist is that you don't have patient contact and so that is why they are not drawn to it.' (Participant 5: Interview 17 May 2013: Durban)

\section{Personal choice regardless of gender}

Specialisations can be selected based on individual characteristics, personal interests as well as talents (Chung et al. 2013; Correia Lima de Souza et al. 2015; Eze et al. 2011). Some participants were of the view that choice of specialisation was unrelated to gender and had more to do with personal choice. As indicated by one of the participants:

'... nothing to do with gender. It is equally split but there are a lot of females. Haematology doesn't restrict it this way. I think its [sic] personal choice.' (Participant 8: Interview 18 May 2013: Durban)

In addition, another respondent indicated that choice of specialisation was quite simple by stating briefly:
'Personal choice.' (Participant 9: Interview on 19 May 2013: Durban)

Personal choice can also be based on the fact that some pathologists have a natural drive to empower and train other pathologists for the benefit of the health system, and simply because they are content with what they do. This is expressed by a participant as follows:

'I am staying here because I need to train more pathologists and I need to provide service to those who are in need- those who cannot afford to go to private for this service. So I am here to provide service for them to train more pathologists and I am happy.' (Participant 11: Interview 20 June 2013: Durban)

\section{Exposure to non-clinical disciplines at medical school}

Exposure to certain disciplines has also been a reason for selecting a speciality. A study by Correia Lima de Souza et al. (2015) indicated extracurricular experiences during medical school as a factor that influenced a corresponding choice of specialisation. Thus, awareness of the various disciplines influences one's choice of medical specialisation. For instance, Participant 2 indicated the following:

'The strange thing is that unfortunately at undergraduate level you don't get exposed to haematology that much. It was my exposure to haematology patients in clinical setting that got me interested in the field. And I really only discovered haematology when I understood what I was getting into and I started doing haematology as a medical officer. Still, working in a clinical department, but we had exposure to the laboratory and we were looking at slides and we were discussing cases. So that is how I got interested.' (Participant 11: Interview 20 June 2013: Durban)

\section{Discussion}

One of the findings of this study illustrated that flexibility within a profession may be an attractive component for deciding on a career, and more specifically a particular speciality within medical laboratory medicine for this case study. Several participants highlighted that laboratory medicine per se is quite flexible and is their reason for selection, more especially the haematology discipline. The haematology discipline itself can be further divided into laboratory and clinical work which boasts increased flexibility making it an attractive career specialisation. This is in line with the literature on flexibility as several writers have linked flexibility with increased job satisfaction and a high level of commitment to employment (Jacob et al. 2008:148; Moen et al. 2016; Richman et al. 2008:190). In addition, workplace flexibility such as family-supportive policies and management could result in an increase in job satisfaction (Jacob et al. 2008:150; Richman et al. 2008:187). Workplace flexibility has a way of acting as a method of retention (Moen et al. 2016; Richman et al. 2008:184).

At this point, it is clear that the core element of Hakim's preference theory - adaptive women - may be applied. Hakim's theory explains that adaptive women will gravitate 
towards employment opportunities that allow for flexibility in order to balance the trade-off between work life and family commitments more effectively. In addition, the socialisation theory adapts to this issue as women are sometimes socialised to understand their duty as a mother once children are born, and thus opt for a more flexible job to accommodate the demands of work-life balance. The socialisation theory highlights that women eventually (at a later stage) take career-related decisions according to needs of their job as well as family, which is evident in the case of most female pathologists in KZN. It is evident through the findings of this study that one's gender is highly influential in the decision of a medical speciality within laboratory medicine. Gender may affect the type of speciality one chooses to pursue (Interview: Participants 5, 6 and 10). It is believed that pathology as a discipline is female dominated as discussed further below. Findings have also revealed that there is a disproportion of males and females within different disciplines, and this form of gender disproportion may be seen as underappreciated (Interview: Participant 13). This is supported by the notion of a disproportionate gender distribution throughout various fields of medical specialisation (Eze et al. 2011; Van TongerenAlers et al. 2013).

Furthermore, participants felt that pathology as a discipline may be viewed as having a stable working environment with hours that attract females (Interview: Participants 2 and 3). A study by Riska (2003:67) based on reasons for a career in pathology illustrated that one of the reasons women chose pathology was because of gendered expectations. The first motivator is the lack of on-duty work, which played a role in career choice (Riska 2003:70). Females generally move into disciplines that have more flexible hours as they are involved in 'traditional' roles and duties of a wife and mother, which are traditional duties as seen by the society (Interview: Participants 2 and 6). Laboratory disciplines were seen to be more appealing to females as they can control their hours (Interview: Participants 1 and 6). Certain fields of pathology, depending on the laboratory rules and regulations, are day based as opposed to after hours which serves as an attraction to females. Again, it is evident that Hakim's notion of 'adaptive women' can be used to explain some of the reasons women choose to remain or pursue certain fields of work, especially in pathology.

Dumelow and Griffiths (cited in Miller \& Clark 2008:241) highlighted the issue of role conflict which included career breaks, childcare and difficulties combining professional and family demands. Also, a study conducted on surgeons by Fitzgerald et al. (2013:114) argued that irrespective of career interests, $59 \%$ of male and $68 \%$ of female participants viewed surgery is not a career welcoming of women. The reasons for this dealt with difficulty maintaining family life and limited flexible training. In this study, and within the pathology field of medicine, it is important to note that many female participants opted for haematology because of flexible working hours that allowed for their role as a wife and mother once they left the laboratory. Studies by Gour et al. (2011), Bhat et al. (2012) and Correia Lima de Souza et al. (2015) have identified the influence of working hours and lifestyle as determining factors of medical careers.

Riska (2003:70) in a study on gender and pathology stated that most Western societies constitute almost half of women in terms of the composition of medical students. However, research conducted by the British Medical Association (cited in Miller \& Clark 2008:240) argues that the distribution of men and women over career grades is disproportionate and the number of women at senior career grades is less as compared to men. In addition, research in the United Kingdom illustrates that female surgeons account for only $10 \%$ of the consultant workforce in the United Kingdom (Fitzgerald et al. 2013:115). However, in the South African context, there has been a large number of females graduating in haematology specifically, so much so that it is difficult to find a male (Interview: Participant 1). Participant 2 explained that in 2011 there were 8 female histopathologists. With regard to the literature that indicates a lack of female graduates, the case of KZN paints a different picture.

Riska (2003) in her study on pathology and gender also demonstrated that working hours were fixed according to a schedule, and there were no calls after hours or on weekends which motivated and attracted more females to this field. A similar trend exists in this study when looking at the discipline of haematology specifically - calls are telephonic instead of being on actual site and are once during the week, again, making this more attractive for females who have the option of taking these calls (emergencies) from the convenience and comfort of their homes. However, it must be noted too that being female, or being a wife or mother, does not necessarily mean that this is the sole reason for deciding to pursue haematology. As one participant indicated she is not even a mother despite her mature age, which indicates that there are other factors owing to her choice of specialisation.

Findings show that anatomical pathology was a field that previously attracted more females than males (Interview: Participant 7). Although anatomical pathologists do not engage in calls over the weekend, their working hours are extensive. Anatomical pathologists have to work from 07:00 to $18: 00$, which might be a reason that females and even males are dissuaded from the discipline (Interview: Participant 6). In light of this, Miller and Clark (2008) illustrated that in $76 \%$ of cases, women leave general medical practise because of family responsibilities. In support of this, Moen et al. (2016) argued the importance of flexibility in employee retention. In terms of the discipline of haematology, however, one will find that females outweigh males at conferences (Interview: Participant 1). Hakim's preference theory may be used to explain the notion of females being driven away through extensive working hours of anatomical pathologists. For instance, Hakim's theory explains that women gravitate towards employment opportunities that are more flexible so as to create a better balance between work and family life; 
however, the theory also adds that in cases where part-time work or flexibility is not available, they either leave fulltime work temporarily or gravitate towards jobs that are more accommodating of their needs (Hakim 2006). Importantly, the assumption that more females are attracted to haematology rather than anatomical pathology because of haematology being a 'soft' job must be avoided as indicated by one of the female participants. The socialisation theory, in a similar manner, may be used to reinforce the notion that for women the role of a wife and mother especially takes precedence because of patterns of socialisation.

Interestingly, however, one of the participants felt that there are more males in private haematology than there were females (Interview: Participant 10). This could be owing to the fact that there were only two haematologists in total in one of the branches of a laboratory in $\mathrm{KZN}$ : one is a male and the other a female.

The bar graph (see Figure 1) is an illustration of the division of gender in the disciplines of anatomical pathology and haematology based on available information regarding the number of males and females. Anatomical pathology has 21 males with just 4 females, whereas haematology has 7 males and 11 females. Anatomical pathology may be seen as a more male-dominated discipline, whereas haematology may be viewed as a female-dominated area. However, one must consider that this does not imply that haematology is a 'soft job', as outlined by an interviewee.

\section{Other factors influencing choice of specialisation}

Another theme that emerged within the findings is that choice of specialisation does not solely depend on gender alone, but other influential factors too. For instance, not all women settled into pathology simply because it offers

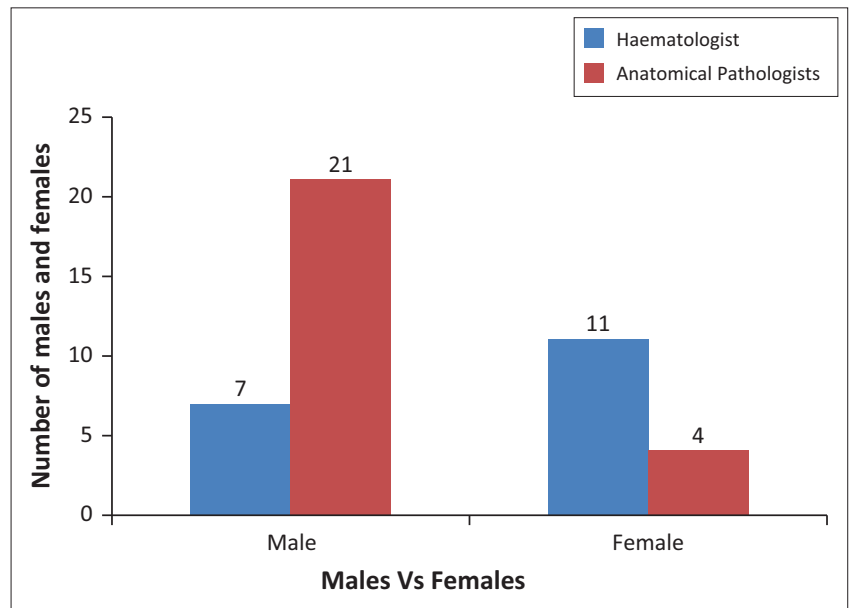

Source: Health Professionals Council of South Africa (HPCSA), 2016, '2016 Registered practitioners', Statistics provided by HPSCA on 07 September 2016

FIGURE 1: Division of gender in the specialisations of anatomical pathology and haematology in KZN. flexibility, or because they are mothers. A study by Riska (2003:59) revealed that content of work rather than hours of work mattered to them. Pathology enabled them to focus on one issue at a time, whereas other specialities were too broad, including demands by patients. Female participants in Riska's (2003) study indicated that the microscope added an aesthetic value that gave medicine a visual dimension that they loved. A female participant in this study indicated that she chose haematology not because of being a mother, but because of personal preferences.

Personal preferences as highlighted in earlier sections of this article have indicated that although gender is influential in career choice, personal preferences are also key determining factors in one's choice of specialisation. As outlined by Participants 1, 2, 8, 9 and 11, there are numerous other reasons to select a particular discipline. Some of these include one's passion, the exposure to a certain field within pathology, experience, as well as the love of training and inspiring future doctors within the field.

On the subject of exposure to the discipline during undergraduate studies, findings showed that exposure of disciplines within pathology to students at undergraduate level plays a role in decisions regarding which field of medical laboratory medicine to pursue. In line with this, the literature revealed that in order to meet this demand of clinical laboratory medicine, the educational requirements for clinical laboratory science have advanced in tandem with the development and expansion of the scope of the field. As a result, early clinical exposure (ECE) as an innovative and active experiential learning methodology applied on patient samples in hospital-based diagnostic laboratories under direct supervision of practising laboratory clinical instructors (Imamwerdi 2013). In relation to findings of this study, one such respondent mentioned that it was unfortunate that they were not exposed to haematology during undergraduate years, and it was through exposure to haematology that she had developed interest in it.

\section{Conclusion}

This study clearly demonstrates the factors contributing to the choice of specialisation within medical laboratory medicine. Most studies focus on women in popular medical fields such as general practice or primary health care. However, this study has emphasised the reasons that account for why women pursue certain disciplines within medicine, specifically the cases of anatomical pathologists and haematologists. Haematology displays a trend of being more attractive to females, whereas anatomical pathology is male dominated. Key elements of the preference theory and socialisation theory aid in explaining the influences women are affected by when selecting a career within medicine, that is, a work-life balance. Although most women choose certain disciplines based on their roles and demands of being a wife and mother, there are others who select careers based on flexibility and scope 
of work, personal preferences, interest and social commitment. This study proves that males enjoy a flexible occupation and have personal interests in certain disciplines irrespective of gender stereotypes that may exist in the medical realm.

\section{Potential human resources for health implications}

Human resources management policy intervention to recruit more doctors into haematology and anatomical pathology should not necessarily focus on different strategies for men and women. However, flexibility does have a gendered dimension. In addition, personal preferences independent of gender are a further driving factor impacting the choice of specialisation and psychometric tests may be one way to tap into the dimensions that make doctors more likely to succeed in non-clinical specialisations. Clearly, the lack of sustained and significant exposure to these disciplines during undergraduate medical school training also needs a policy intervention.

\section{Acknowledgements Competing interests}

The authors declare that they have no financial or personal relationships which may have inappropriately influenced them in writing this article.

\section{Author's contributions}

S.S. and S.R. equally contributed to the research and writing of this article.

\section{References}

Babbie, E. \& Mouton, J., 2009, The practice of social research, Oxford University Press Southern Africa, Cape Town.

Bhat, S., D'souza, L. \& Fernandez, J., 2012, 'Factors influencing the career choices of medical graduates', Journal of Clinical and Diagnostic Research 6(1), 61-64.

Brandis, S., Fitzgerald, A., Avery, M., McPhail, R. \& Booth, J., 2015, 'The emergence of new kinds of professional work within the health sector', in A. Wilkinson, D. Hislop \& C. Coupland (eds.), Perspectives on contemporary professional work: Challenges and experiences, pp. 232-258, Edward Elgar Publishing Ltd.

Braun, V. \& Clarke, V., 2006, 'Using thematic analysis in psychology', Qualitative Research in Psychology 3(2), 77-101. http://dx.doi.org/10.1191/1478088706 qp063oa

Bryman, A. \& Bell, E., 2007, Business research methods, 2nd edn., Oxford University Press Inc., New York.

Burton, D., 2000, Research training for social scientists, Sage, London.

Carter, J.M., 2014, 'Gender socialisation and identity theory', Social Sciences 3(2), 242-263. http://dx.doi.org/10.3390/socsci3020242

Cassim, N. \& Ruggunan, R., 2014, 'A qualitative study of the factors influencing the global migration of anatomical pathologists in KwaZulu-Natal, South Africa', Health SA Gesondheid 19(1), 1-9.

Chung, Y.C., Lin, C.Y., Huang, C.N. \& Yang, J.H., 2013, 'Perceptions on gender awareness and considerations in career choices of medical students in a medical school', Taiwan Kaohsiung Journal of Medical Sciences 29(11), 629-635. http://dx.doi. org/10.1016/j.kjms.2013.01.014

Correia Lima de Souza, L., Mendonça, V.R.R., Garcia, G.B.C., Brandão, E.C. \& BarralNetto, M., 2015, 'Medical specialty choice and related factors of Brazilian medical students and recent doctors', PLOS One 10(7), e0133585. http://dx.doi.org/10. 1371/journal.pone.0133585

Drexel University College of Medicine, 2014, 'Laboratory medicine', viewed 15 November 2014, from https://www.drexelmed.edu/

Edwards, R. \& Holland, J., 2013, 'What is qualitative interviewing?', viewed 28 August 2016, from http://eprints.ncrm.ac.uk/3276/1/complete_proofs.pdf
Etikan, I., Musa, S.A. \& Alkassim, R.S., 2016, 'Comparison of convenience sampling and purposive sampling', American Journal of Theoretical and Applied Statistics 5(1), 1-4. http://dx.doi.org/10.11648/j.ajtas.20160501.11

Eze, B.I., Okoye, O.I., Maduka-Okafor, F.C. \& Aguwa, E.N., 2011, 'Factors influencing choice of medical specialty of preresidency medical graduates in southeastern Nigeria', Journal of Graduate Medical Education 3(3), 367-371. http://dx.doi.org/10. 4300/JGME-D-10-00101.1

Fitzgerald, J.E.F., Tang, S.W., Ravindra, P. \& Maxwell-Armstrong, C.A., 2013, 'Genderrelated perceptions of careers in surgery among new medical graduates: Results of a cross-sectional study', The American Journal of Surgery 206(1), 112-119. http://dx.doi.org/10.1016/j.amjsurg.2012.04.009

Gour, N., Srivastava, D., Adhikari, P., Shahi, A., Sharma, M.K. \& Mahajan, P.C., 2011, 'Specialty preference among medical students and factors affecting it', Online Journal of Health and Allied Sciences 10(2), 12.

Gummesson, E., 2000, Qualitative methods in management research, Sage, London.

Hajjaj, F.M., Selak, M.S., Basra, M.K. \& Finlay, A.Y., 2010, 'Non-clinical influences on clinical decision-making: A major challenge to evidence-based practice', Journal of the Royal Society of Medicine 103(5), 178-187. http://dx.doi.org/10.1258/ jrsm.2010.100104

Hakim, C., 2006, 'Women, careers, and work-life preferences', British Journal of Guidance and Counselling 34(3), 279-294. http://dx.doi.org/10.1080/03069 880600769118

Hakim, C., 2011, 'Feminist myths and magic medicine: The flawed thinking behind calls for further equality legislation', LSE Research Online, viewed 10 November 2014, from http://eprints.Ise.ac.uk/36488/

Heald, B., Rybicki, L., Clements, D., Marquard, J., Mester, J., Noss, R. et al., 2016, 'Assessment of clinical workload for general and specialty genetic counsellors at an academic medical center: A tool for evaluating genetic counselling practices', NPJ Genomic Medicine 1, 16010. http://dx.doi.org/10.1038/npjgenmed.2016.10

Health Professionals Council of South Africa (HPCSA), 2016, '2016 Registered practitioners', Statistics provided by HPSCA on 07 September 2016.

Holleyman, R. \& Jones, S.V., 2016, 'Location, vocation, procreation: How choice influences life expectancy in doctors', Occupational Medicine 207. http://dx.doi. org/10.1093/occmed/kqv207

Hongoro, C., Funani, I.N., Chitha, W. \& Godlimpi, L., 2016, 'An assessment of private General Practitioners contracting for public health services delivery in OR Tambo District, South Africa', Journal of Public Health in Africa 6(2). http://dx.doi. org/10.4081/jphia.2015.525

Imamwerdi, B.W., 2013, 'The effects of early clinical exposure on medical laboratory technology students: Its effect on internship period and their professional carrier', WebMed Central, viewed 15 December 2014, from http://www.webmedcentral. com/article_view/3926

Jacob, J.I., Bond, J.T., Galinsky, E. \& Hill, E.J., 2008, 'Six critical ingredients in creating an effective workplace', The Psychologist-Manager Journal 11, 141-161. http:// dx.doi.org/10.1080/10887150801967704

Joyce, C., Eyre, H., Wang, W.C. \& Laurence, C., 2015, 'Australian doctors' non-clinical activities: Results from the medicine in Australia: Balancing employment and life (MABEL) survey of doctors', Australian Health Review 39(5), 588-594. http://dx. doi.org/10.1071/AH14223

Judger, N., 2016, 'The thematic analysis of interview data: An approach used to examine the influence of the market on curricular provision in Mongolian higher education institutions', viewed 28 August 2016, from http://2gupzkho2c1wvo8kk58b6cpr. wpengine.netdna-cdn.com/files/2016/02/HPP2016-3-Jugder.pdf

Lu, J., 2016, 'Will medical technology deskill doctors?', International Education Studies 9(7), 130. http://dx.doi.org/10.5539/ies.v9n7p130

Maier, C.B. \& Aiken, L.H., 2016, 'Expanding clinical roles for nurses to realign the global health workforce with population needs: A commentary', Israel Journal of Health Policy Research 5(21), 1. http://dx.doi.org/10.1186/s13584-016-0079-2

Manea, L.R., 2007, 'Hakim's preference theory in the Czech context', Demografie 49, $77-86$.

Michel, R., 2016, 'Critical shortage of pathologists in Africa triggers calls for more training programs and incentives to increase the number of skilled histopathologists', Dark Daily, Clinical laboratory and pathology, news and trends, viewed 29 April 2016, from http://www.darkdaily.com/critical-shortage-ofpathologists-in-africa-triggers-calls-for-more-training-programs-and-incentivesto-increase-the-number-of-skilled-histopathologists\#axzz4JNEdCmYo

Miller, K. \& Clark, D., 2008, “"Knife before wife”: An exploratory study of gender and the UK medical profession', Journal of Health Organization and Management 22(3), 238-253. http://dx.doi.org/10.1108/14777260810883521

Moen, P., Kojola, E., Kelly, E.L. \& Karakaya, Y., 2016, 'Men and women expecting to work longer: Do changing work conditions matter?', Work, Aging and Retirement 2(3), 321-344. http://dx.doi.org/10.1093/workar/waw018

Naidoo, S., 2012, 'The South African national health insurance: A revolution in healthcare delivery!', Journal of Public Health 34(1), 149-150. http://dx.doi.org/10.1093/ pubmed/fds008

Pathcare, 2015, 'Student Medical Laboratory Technician Programme', viewed 08 September 2016, from https://www.pathcare.co.za/pages/pathcare-med-labprog.html

Raghuram, P. \& Kofman, E., 2002, 'The state, skilled labour markets, and immigration: The case of doctors in England', Environment and Planning 34(11), 2071-2089. http://dx.doi.org/10.1068/a3541

Reich, A.D., Hansen, H.B. \& Link, B.G., 2016, 'Fundamental interventions: How clinicians can address the fundamental causes of disease', Journal of Bioethical Inquiry 13(2), 1-8. http://dx.doi.org/10.1007/s11673-016-9715-3 
Richman, A.L., Civian, J.T., Shannon, L.L., Hill, J. \& Brennan, R.T., 2008, 'The relationship of perceived flexibility, supportive work-life policies, and use of formal flexible arrangements and occasional flexibility to employee engagement and expected retention', Community, Work and Family 11(2), 183-197. http://dx.doi.org/10. 1080/13668800802050350

Riska, E., 2003, 'The career and work of pathologists: A gender perspective', The International Journal of Sociology and Social Policy 23(4/5), 59-79. http://dx.doi. org/10.1108/01443330310790516

Royal College of Pathology of Australia, 2011, Royal College of Pathologists, viewed 16 October 2014, from http://www.rcpath.org/

Ruggunan, S., 2013, 'Labour process and professional status: An exploratory case study of histopathologists in Kwazulu-Natal', South African Review of Sociology 44(2), 98-111. http://dx.doi.org/10.1080/21528586.2013.802541

Ruggunan, S.D. \& Singh, S., 2013, 'Sector switching among histopathologists in KwaZulu-Natal, South Africa: A qualitative study', Human Resources for Health 11(23), 2-11. http://dx.doi.org/10.1186/1478-4491-11-23

Saunders, M., Lewis, P. \& Thornhill, A., 2012, Research methods for business students, 6th edn., Pearson Education Limited, Essex.

School of Laboratory Medicine \& Medical Sciences, UKZN, viewed 01 September 2014, from http://slmms.ukzn.ac.za/Homepage.aspx
Singh, S., 2013, 'A case study of private-public sector labour market mobilities of South African medical laboratory specialists', viewed 23 November 2014, from http://researchspace.ukzn.ac.za/xmlui/bitstream/handle/10413/7495/Singh Suveera_2012.pdf?sequence=1

Tsiko, S., 2016, 'Shortage of pathologists cripple region's healthcare system', The Southern Times, 03 March, viewed 07 September 2016, from http://southernafrican . news/2016/03/03/shortage-of-pathologists-cripple-regions-healthcare-system/

Van Tongeren-Alers, M., Verdonk, P., Bor, H., Johansson, E.E., Hamberg, K. \& LagroJanssen, A., 2013, 'How gender or culture affects first year Dutch and Swedish students' preferences for specialties and work-life issues', International Journal of Medical Education 4, 214-220. http://dx.doi.org/10.5116/ijme.5259.7845

Vitali, A., Bilarri, F.C., Prskawetz, A. \& Testa, M.R., 2009, 'Preference theory and low fertility: A comparative perspective', 1-36, viewed 10 August 2014, from www. oeaw.ac.at/vid/download/edrp_2_07.pdf

Yee Kan, M., 2005, 'Work orientation and wives' employment careers: An evaluation of Hakim's preference theory', viewed 12 August 2014, from https://www.iser. essex.ac.uk/files/iser_working_papers/2005-27.pdf

Young, R., Nobel, J., Hann, M. \& Sibbald, B., 2003, The international market for medical doctors: Perspectives on the positioning of the UK, National Primary Care Research and Development Centre, Manchester, United Kingdom. 